Nigerian Veterinary Journal Vol. 26 (2), 2005

\title{
CARPAL ARTHRODESIS FOR THE MANAGEMENT OF EXPERIMENTALLY INDUCED RADIAL NERVE PARALYSIS IN DOGS
}

\author{
HASSAN ${ }^{1}$, A.Z., ADEYANJU ${ }^{2}$, J.B., HASSAN ${ }^{3}$, F.B., REMI-ADEWUMI* ${ }^{1}$, B.D., \\ KADIMA, ${ }^{1}$ K.J. AND AWASUM ${ }^{1}$, C.A. \\ ${ }^{\prime}$ Veterinary Surgery and Medicine Department, Ahmadu Bello University, Zaria \\ ${ }^{2}$ Veterinary and Theriogenology Department, Usman Danfodio University, Sokoto \\ ${ }^{3}$ Division of Agric. Colleges, Ahmadu Bello University, Zaria
}

*Corresponding Author

\section{SUMMARY}

Experimentally resecting the radial nerve at mid-humerus in nine (9) dogs resulted in the distal forelimb paralysis. The dogs were evaluated for stance, toe pinch, gait and extent of cutaneous desensitization. Three weeks post surgery, three animals in the control group showed improvement in stance and gait while the fourth remained lame to the end of the study. Five dogs underwent arthrodesis by the use of Kirschner wires in a cruciate fashion to immobilize the carpal joint. Limb usage was generally satisfactory within 7 days. Migration or shifting of the pin (1 case) was the only complication associated with this procedure.

KEY WORDS: Phantom arthrodesis, Medicine, Surgery Management, Radial nerve paralysis, Dogs

\section{INTRODUCTION}

Peripheral nerve damage refers to any form of trauma or lesion to a peripheral nerve. This often results in disruption of the functions of such a nerve resulting in a paresis. A combination of sensory, voluntary motor and reflex abnormalities are often exhibited by animals having peripheral nerve damage such as radial and peroneal nerve damage (Jacobson and Schrauder, 1987). Numerous sources of traumatic injury to peripheral nerves exist such as fractures (e.g. radial nerve damage in humeral fractures); lacerations; gun shot injuries; inadvertent severance during surgical procedures (e.g. sciatic nerve damage in surgical management of coxofemoral luxations); peroneal nerve paralysis following injury due to intramuscular administration of medications and neoplastic malignancies (Swaim, 1984; Chambers and Hardie,
1986; Wilner and Brody, 1986) have been described.

A diagnosis of radial nerve as well as other peripheral nerve paralysis is often made by a combined application of careful clinical and neurological examinations (Duncan, 1980). Neuroanastomois, muscle relocation, musculotendinous transposition and joint ankylosis/arthrodesis have been undertaken to salvage paralyzed forelimbs in animals. However, numerous shortcomings and or complications of the aforementioned standard techniques such as increased risk of fractures and degenerative joint conditions as well as delayed healing warrant re-evaluation of these techniques.

This study was undertaken to modify the carpal arthrodesis protocol and to standardize this management technique for routine use in the management of clinical 
radial nerve paralysis in veterinary patients.

\section{MATERIALS AND METHOD}

Experimental Animals: Nine (9)

Nigerian Indigenous Dogs (NIDs) randomly divided into 2 groups (I and II) were used for this study. The dogs were housed and fed individually in the Veterinary Teaching Hospital Kennels.

Pre-surgical Evaluation: All dogs were thoroughly examined, dewormed with pyrantel pamoate (Combantrin ${ }^{\circledR}$ Neimeth. Ikeja) and praxiquantel (Droncit ${ }^{\circledR}$ Bayer Germany) at $5 \mathrm{mg} / \mathrm{kg}$ and $10 \mathrm{mg} / \mathrm{kg}$ respectively. Ectoparasitic control was achieved by topical application of $2 \mathrm{ml}$ flumethrin Bayticol Pour-on(B) (Bayer Germany).

Surgery: Standard general and orthopedic sterile packs were utilized for all surgeries. Atropine sulphate at $0.02 \mathrm{mg} / \mathrm{kg}$ and Chlorpromazine at $2 \mathrm{mg} / \mathrm{kg}$ were used as preanesthetic agents. Sodium Pentobarbitone at $10-15 \mathrm{mg} / \mathrm{kg}$ intravenously, was administered to achieve anesthesia. Both surgical team and patient preparations were in accordance with standard procedures as described by Bojrab, (1985); Powers, (1985); Wagner, (1985) and Knecht et al. (1987).

Exposure of the radial nerve in all cases was via the lateral ante brachial approach (Fig. 1) as described by Piemattei and Greely, (1979).

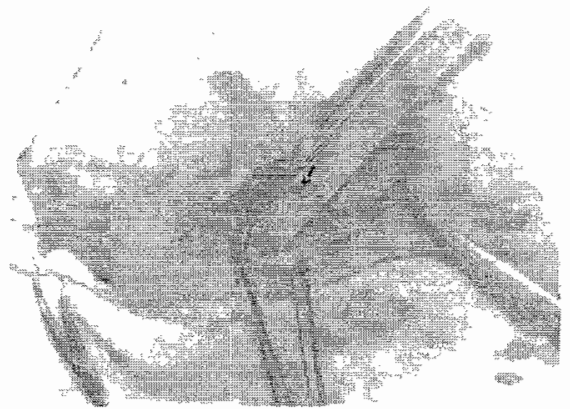

Fig. 1: Lateral antebrachial incision and exteriorization of the radial nerve
The radial nerve proximal to its point of bifurcation was exteriorized (Fig. 1), transected and a centimeter removed to effect paralysis and prevents reestablishment of contact. Closure of the incision was achieved by the routine 3 layered closure using $2 / 0$ chromic catgut for the muscle and subcutaneous layers and $2 / 0$ nylon for the skin.

The control (Group I) consisted of 4 dogs (Cases 1, 2, 3 and 4). No post surgical management was undertaken. The experimental group (Group II) comprising of 5 dogs (Cases 5, 6, 7, 8 and 9) had the affected carpus fully extended and 2 Kirschner wires introduced in a cruciate fashion (Fig. 2). These pins were introduced to incorporate the distal radioulnar, the carpus as well as the metacarpals to stabilize and immobilize the carpal joint.

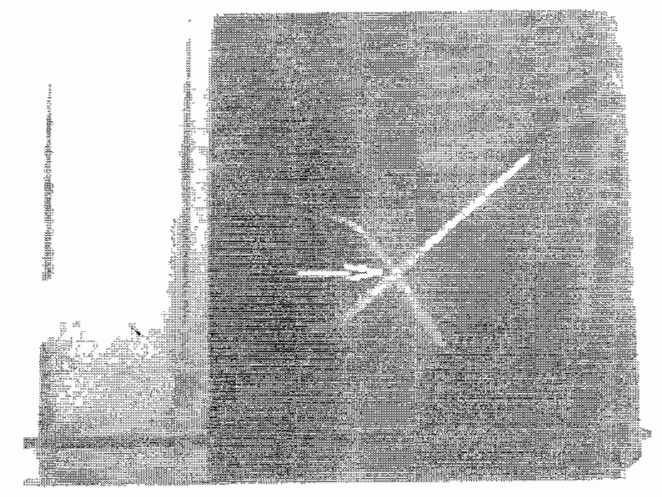

Fig. 2: Cruciate pinning of the carpus with Kirschner wires

Evaluation of Neural Dysfunction: The stance, gait, toe pinch reflex as well as the extent and level of cutaneous desensitization were evaluated as indices of neural dysfunction. These evaluations were conducted on both forelimbs and discrepancies between the normal and paralyzed limb were noted. 
RESULTS

A summary of the post surgical findings in all the dogs over a 180-day period is presented in Tables I and II. The exteriorization and resection of the radial nerve was readily accomplished. Features of neural disorders noticed included the inability of the dogs to place weight on the paralyzed limb; knuckling and occasional falling over as the animal walks; loss of response to the toe pinch and desensitization of the dorsum of the carpus, metacarpus as well as digits of the affected limb. Both the stance and gait improved 30 - 60 days post surgery in case 1, 2 and 4 (Table I). In case 3 however, marked gait abnormalities persisted to the end of the study.

TABLE I: $\quad$ Response of control (Group 1) dogs 1-4 following experimental radial nerve transaction

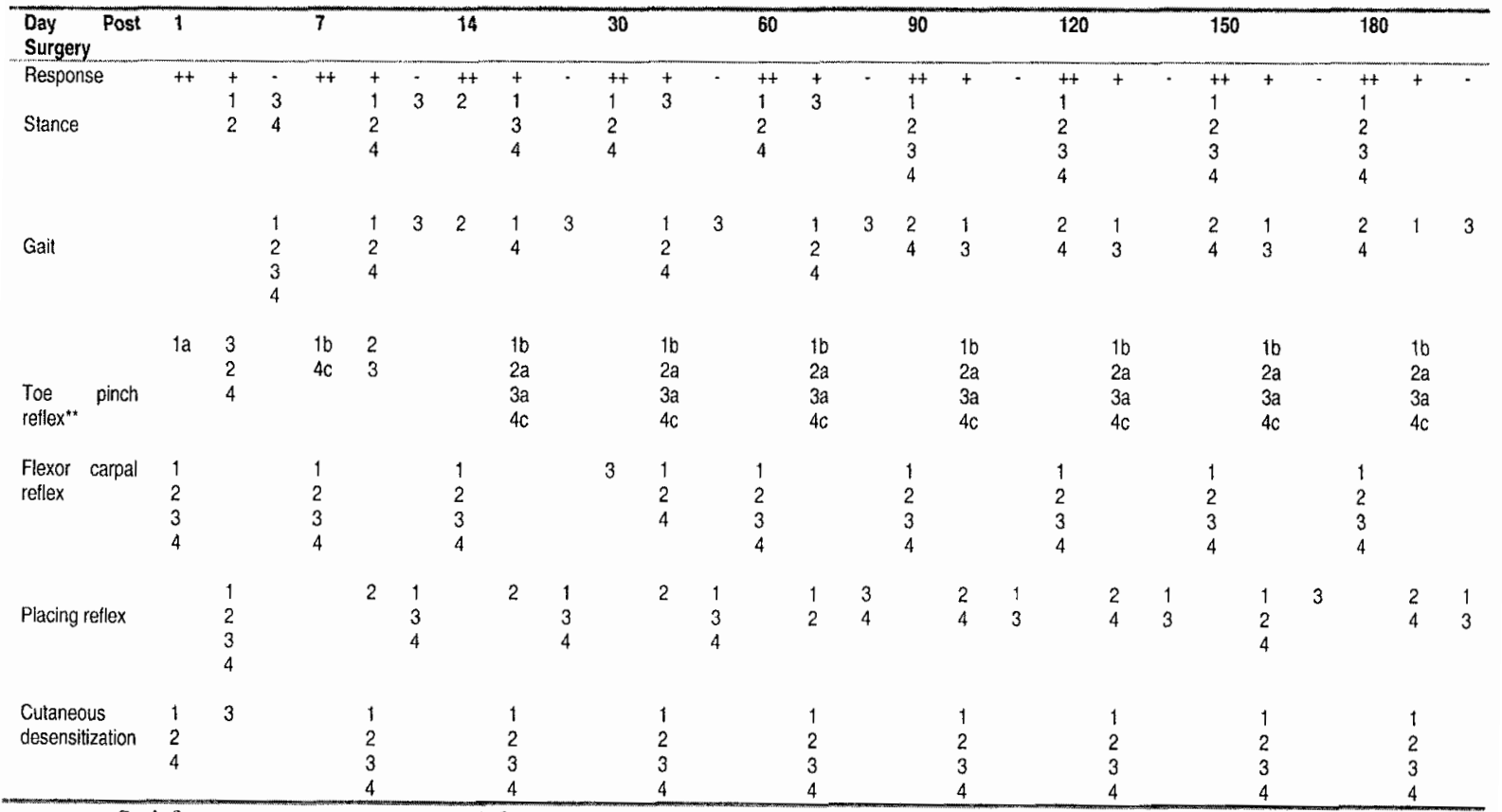

$++=$ Satisfactory response; $+=$ Unsatisfactory response; $-=$ Negative response

**: $\mathrm{a}=\operatorname{digit} 5$ only; $\mathrm{b}=\operatorname{digits} 2$ and $5 ; \mathrm{c}=\operatorname{digit} 2$ only

A summary of the post-surgical observations for Group II is presented in Table II. Locomotor disturbances following cross pinning of the carpus though present permitted the use of the affected limb. All the dogs except case 6 could bear weight on the affectyed limb within 7 days of the surgery, the gait however remained abnormal. Partial migration of the pins in Case 5 resulted in flexion and arthrodesis of the affected carpus in a flexed position. In a similar case (case 7) pin migration occurred within 30 days of placement and was promptly re-introduced resulting in a stable arthrodesis by day 60 . Response to the toe pinch reflex in Group II was as observed for Group I (controls) with elicitation of response on digit $\mathrm{V}$ in all cases. Cases 7, 8 and 9 also showed some response on pinching digit II. The dorsum of the ante brachium, carpus and digits except the fifth were generally desensitized. 
Nigerian Veterinary Journal Vol. 26 (2), 2005

TABLE II: Response of control (Group 2) dogs 5-9 following experimental radial nerve transaction and carpal arthrodesis

\begin{tabular}{|c|c|c|c|c|c|c|c|c|c|c|c|c|c|c|c|c|c|c|c|c|c|c|c|c|c|c|c|}
\hline $\begin{array}{l}\text { Day Post } \\
\text { Surgery }\end{array}$ & 1 & & & 7 & & & 14 & & & 30 & & & 60 & & & 90 & & & 120 & & & 150 & & & 180 & & \\
\hline Response & $+t$ & $\begin{array}{l}+ \\
5\end{array}$ & - & $\begin{array}{l}++ \\
5\end{array}$ & $\begin{array}{l}+ \\
6\end{array}$ & $\cdot$ & $\begin{array}{l}++ \\
5\end{array}$ & $\begin{array}{l}+ \\
6\end{array}$ & - & $\begin{array}{l}+t \\
5\end{array}$ & + & 6 & $\begin{array}{l}++ \\
7\end{array}$ & + & 5 & $\begin{array}{l}++ \\
7\end{array}$ & + & 5 & $\begin{array}{l}++ \\
7\end{array}$ & $\begin{array}{l}t \\
5\end{array}$ & $\cdot$ & $\begin{array}{l}++ \\
7\end{array}$ & $\begin{array}{l}t \\
5\end{array}$ & 6 & $\begin{array}{l}++ \\
7\end{array}$ & $\begin{array}{l}+ \\
5\end{array}$ & $\cdot$ \\
\hline Stance & & $\begin{array}{l}7 \\
8 \\
9\end{array}$ & & $\begin{array}{l}7 \\
8 \\
9\end{array}$ & & & $\begin{array}{l}7 \\
8 \\
9\end{array}$ & & & $\begin{array}{l}7 \\
8 \\
9\end{array}$ & & & $\begin{array}{l}8 \\
9\end{array}$ & & 6 & $\begin{array}{l}8 \\
9\end{array}$ & & 6 & $\begin{array}{l}8 \\
9\end{array}$ & 6 & & $\begin{array}{l}8 \\
9\end{array}$ & & & $\begin{array}{l}8 \\
9\end{array}$ & 6 & \\
\hline Gait & & $\begin{array}{l}7 \\
8\end{array}$ & $\begin{array}{l}5 \\
6 \\
9\end{array}$ & & $\begin{array}{l}6 \\
7 \\
8 \\
9\end{array}$ & 5 & & $\begin{array}{l}5 \\
6 \\
7 \\
8 \\
9\end{array}$ & & & $\begin{array}{l}5 \\
7 \\
8 \\
9\end{array}$ & 6 & & $\begin{array}{l}7 \\
8 \\
9\end{array}$ & $\begin{array}{l}5 \\
6\end{array}$ & & $\begin{array}{l}5 \\
7 \\
8 \\
9\end{array}$ & 6 & & $\begin{array}{l}5 \\
7 \\
8 \\
9\end{array}$ & 6 & & $\begin{array}{l}5 \\
7 \\
8 \\
9\end{array}$ & 6 & & $\begin{array}{l}5 \\
7 \\
8 \\
9\end{array}$ & 6 \\
\hline Toe pinch & & $\begin{array}{l}7 c \\
8 c\end{array}$ & $\begin{array}{l}5 \\
6 \\
9\end{array}$ & & $\begin{array}{l}6 a \\
7 a \\
8 a \\
9 a\end{array}$ & 5 & & $\begin{array}{l}5 a \\
6 a \\
7 c \\
8 b \\
9 b\end{array}$ & & & $\begin{array}{l}5 a \\
6 a \\
7 c \\
8 b \\
9 b\end{array}$ & & & $\begin{array}{l}5 a \\
6 a \\
7 c \\
8 b \\
9 b\end{array}$ & & & $\begin{array}{l}5 a \\
6 a \\
7 c \\
8 b \\
9 b\end{array}$ & & & $\begin{array}{l}5 a \\
6 a \\
7 c \\
8 b \\
9 b\end{array}$ & & & $\begin{array}{l}5 a \\
6 a \\
7 c \\
8 b \\
9 b\end{array}$ & & & $\begin{array}{l}5 a \\
6 a \\
7 c \\
8 b \\
9 b\end{array}$ & \\
\hline $\begin{array}{l}\text { Cutaneous } \\
\text { desensitization }\end{array}$ & & $\begin{array}{l}5 \\
6 \\
8 d\end{array}$ & $\begin{array}{l}7 \\
9\end{array}$ & & $\begin{array}{l}6 \\
7 d \\
8 \\
9 \\
5\end{array}$ & & 7 & $\begin{array}{l}5 \\
6 \\
8 \\
9\end{array}$ & & 7 & $\begin{array}{l}5 \\
6 \\
8 \\
9\end{array}$ & & 7 & $\begin{array}{l}5 \\
6 \\
8 \\
9\end{array}$ & & 7 & $\begin{array}{l}5 \\
6 \\
8 \\
9\end{array}$ & & 7 & $\begin{array}{l}5 \\
6 \\
8 \\
9\end{array}$ & & 7 & $\begin{array}{l}5 \\
6 \\
8 \\
9\end{array}$ & & 7 & $\begin{array}{l}5 \\
6 \\
8 \\
9\end{array}$ & \\
\hline
\end{tabular}

$++=$ Satisfactory response $+=$ Unsatisfactory response; $-=$ Negative response

$* * a=\operatorname{digit} 5$ only; $b=\operatorname{digits~} 2$ and $5 ; c=$ digit 2 only; $d=$ response on digit 2 and metacarpal area

\section{DISCUSSION}

Exposure and resection of the radial nerve in the mid humerus was undertaken because this is often the point of radial nerve traumatizatrion in canine humeral fractures as the radial nerve courses through the musculospiral groove of the humeral bone. Paralysis of the carpal and digital extensors were observed as earlier reported (Hussain and Ghery, 1967), a delayed but subsequent use of the flexors was also noticed. In most cases however, complete desensitization of the dorsum of the ante brachium, carpus and digits was not achieved as was expected based on the supposed singular innervation of these areas by the radial nerve (Miller et al., 1964; Sisson and Grossman, 1975)." This suggests an additional or supplementary innervation of these areas possibly by a branch of the ulnar nerve. The ability of some of the dogs to mildly extend the digits also supports this assertion.
As opposed to an earlier report by Hussain and Ghery (1967) of difficulty in detecting any paralysis from day 10 post surgery, this study showed varying levels of locomotor disturbances, which in one case persisted to the end of the study ( Table I). These disturbances range from impaired stance and gait to knuckling when the dogs attempt walking. The level of limb usage noted in cases 1,2 and 4 indicate that some dogs do overcome this form of paralysis even without surgical intervention which was by flipping the limb prior to it's placement as the dog moves around. The inability of case 3 to overcome the disability resulted in severe bruises on the dorsum of the digits. In such a case surgical intervention may be beneficial in saving the limb from a possible amputation should extensive trauma and sepsis ensue. 
Restoration of limb function was achieved following false arthrodesis of the affected carpus. Except in case 6, the stance in the other dogs was satisfactory on or before day 7 post surgery. Gait however, remained abnormal as expected due to the immobilization of the carpus. Migration of the pins used for cross spinning the carpus was the only problem encountered. The use of threaded pins or bending the proximal and of the pin was later shown to prevent this migration. False arthrodesis as was employed in this study achieves stability of the joints by fibrosis and not bony fusion. This form of arthrodesis decreases the stress place on adjacent long bones because of the more elastic and projected superior shock absorbing nature of the fibrous tissue bridging the carpus and subsequently a decrease in the likelihood of stress fractures. Our success in arthrodesing the carpus following radial nerve paralysis seem to be at variance with the position of some authors (James, 1991). Furthermore, we have successfully undertaken this protocol in dogs of up to $20 \mathrm{~kg}$.

In conclusion, it was realized that within 3 weeks, an improvement in both stance and gait were noticed in some of the experimental dogs, which, underwent resection of the radial nerve with the associated paralysis even without surgical intervention. However, stance and gait abnormalities were so severe in other dogs leading to traumatization of the affected limb. In light of this finding, restraint for at least 3 weeks is suggested before surgical management is contemplated as we noticed that cases likely to markedly without any intervention would do so within a 3 -week period. If however, the paralysis is associated with a concomitant fracture, the fracture should be allowed to heal appreciably to fully assess the severity of neural damage. False arthrodesis was shown to be a satisfactory, viable and a feasible alternative to limb amputation in cases of radial nerve damage in dogs, which fail to gain functional limb use following the application of more conservative management options.

\section{REFERENCES}

BOJRAB, M.J. (1985): Arthrodesis. In: Current Techniques in Small Animal Surgery. Lea and Febiger. Philadelphia. Pp.343, 542 - 549.

CHAMBERS, J.N. and HARDIE, E.M. (1986): Paralysis of the sciatic nerve. J. Am. Anim. Hosp. Assoc. 2: 539 .

DUNCAN, I.D. (1980): Neurology. In: Veterinary Clinics of North America. Small Anim. Pract. 10: 177.

HUSSAIN, S. and GHERY, D.P. (1967): Tendon transplantation for radial nerve paralysis. Am. J. Vet. Res. 28: 335 - 344 .

JACOBSON, A. and SCHRAUDER, S.C. (1967): Peripheral nerve injury associated with fractures or fracture dislocations of the pelvis in dogs and cats. A review of 34 cases (1978 - 1982). J. Am Vet. Med. Assoc. 190: $509-572$.

JAMES, C.R. (1991): Salvage procedures in canine orthopedics. $2^{\text {nd }}$ edn. Williams Whittick (ed). Lea and Febiger Philadelphia. P.90.

KNECHT, O.D. ALLEN, A.R, WILLIAMS, D.J. and JOHNSON, J.H. (1987): Fundamental Techniques in Veterinary Surgery. $3^{\text {rd }}$ edn. W.B. Saunders, Philadelphia. Pp.82 - 99.

MLLLER, M.E., CHRISTENSEN, G.C. and EVANS, H.E.: The Anatomy of the Dog. W.B. Saunders, Philadelphia. 1964. Pp. 212, 219. 
PIEMATTEI, D.L. and GREELY, R.G. (1979): An Atlas of Surgical Approaches to the Bones of the Dog and Cat. $2^{\text {nd }}$ edn. W.B. Saunders. Philadelphia. Pp.279.

POWERS, D.L. (1985): Surgical patient preparation. In: Textbook of Small Animal Surgery. Slatter E.B. (ed). W.B.- Saunders, Philadelphia`'Pp. 279.

SISSION S. and GROSSMAN, J.O., (1985): Canine mycology. In: The Anatomy of the Domestic Animals. Vol. II. Getty, R. (ed). $5^{\text {th }}$ Edn.
W.B. Saunders. Philadelphia. Pp. $1699-1704$.

SWAIM, S.F. (1984): Peripheral nerve surgery. In: Proceedings of the $9^{\text {th }}$ Annual Veterinary Surgical Forum. Chicago. Illinois, Pp. $1-10$.

WAGNER, S.D. (1985): Surgical team preparation. In: Textbook of Small Animal Surgery. Slatter F.B. (ed). W.B. Saunders. Philadelphia. Pp.283.

WILNER, E.C. and BRODY, J.A. (1986): An evaluation of the remote effects of cancer on the nervous system. Neurology. 18: 1120 - 1124. 